CARDIOVASCULAR MEDICINE

\title{
Myocardial viability assessed by dobutamine stress echocardiography predicts reduced mortality early after acute myocardial infarction: determining the risk of events after myocardial infarction (DREAM) study
}

\author{
J M A Swinburn, R Senior
}

See end of article for authors' affiliations

Correspondence to:

Dr Roxy Senior

Department of

Cardiovascular Medicine

Northwick Park Hospital,

Watford Road, Harrow,

Middlesex HA1 3UJ, UK

roxy.senior@virgin.net

Accepted 7 April 2005

Published Online First

14 April 2005
Objective: To establish further the role of dobutamine stress echocardiography (DSE) in prognostication of outcome early after acute myocardial infarction (AMI)

Methods: Consecutive patients presenting with AMl were screened for inclusion into the study. 212 stable consenting patients underwent DSE a mean (SD) of 4.8 (1.5) days after AMI. Patients were then followed up for 803 (297) days.

Results: The mean (SD) resting systolic wall thickening index (SWTI) was $1.6(0.4), 44 \%$ patients had evidence of viability at low dose, and $38 \%$ had evidence of ischaemia. During the follow up period 27 (13\%) patients died and $16(8 \%)$ had a non-fatal AMI. Independent predictors of both mortality and combined mortality and non-fatal AMI were age (hazard ratio (HR) 1.04/year, $p=0.01$, and HR 1.03/ year, $p=0.04$, respectively) and SWTI at low dose (HR 3.6, $p<0.01$, and HR 2.5, $p=0.02$, respectively). Low dose DSE provided incremental information over clinical and resting left ventricular function data for predicting death and non-fatal AMI. For patients who were not revascularised SWTI at peak dose dobutamine was the only independent predictor of mortality.

Conclusion: DSE is a powerful predictor of outcome in stable survivors of AMI. The presence of myocardial viability has a positive impact on survival.
$\mathrm{R}$ isk stratification is a crucial component of the management of patients after acute myocardial infarction (AMI). A significant proportion of patients manifest clinical features that are associated with high risk, such as postinfarction angina, heart failure, or haemodynamic instability, and these patients require an aggressive invasive management strategy. The remaining patients, however, have a broad spectrum of risk that is not clinically apparent and need further investigation to elucidate the extent of this risk.

Whereas resting left ventricular ejection fraction (LVEF) is a well recognised and important marker of prognosis, in the early postinfarction period viability and function may be uncoupled, ${ }^{1}$ such that if significant amounts of stunned or hibernating myocardium are present then resting LVEF substantially underestimates the true contractile potential of the ventricle. In the context of stable coronary artery disease several observational studies have indicated that patients with viable but ischaemic myocardium have a worse outcome if treated medically rather than revascularised..$^{2-4}$ Dobutamine stress echocardiography (DSE) has been extensively used for risk stratification of patients after AMI, but there is some disparity between studies as to the prognostic implication of various components of the dobutamine response. $^{5-9}$ This study was conducted to determine further the role of DSE in the assessment of survivors of AMI who are asymptomatic and haemodynamically stable.

\section{METHODS}

Consecutive patients presenting to our institution with AMI were screened for inclusion in this prospective study. From a total of 620 patients, 212 stable and consenting patients were recruited. A diagnosis of AMI was based on the presence of at least two of the following three features: typical cardiac chest pain, ECG ST segment elevation, and a creatine kinase concentration greater than twice the upper limit of normal. All patients presenting to our institution during the study period (May 1998 to July 2000) were screened for inclusion into the study. Patients were excluded if they had evidence of ongoing ischaemia, haemodynamic instability, or significant co-morbidity. The study patients then underwent DSE at least three days after admission and were followed up for subsequent adverse clinical events. $\beta$ Blockers were stopped for two days before DSE. All clinical management decisions were taken by physicians who were not involved in the study and who were unaware of the results of DSE. Coronary angiography was performed on clinical grounds only and was not a requirement of the study protocol. The study was approved by the local ethics committee.

\section{Echocardiography}

Echocardiography was performed with a broadband transducer (4 to $2 \mathrm{MHz}$ ) on an HDI 3000 (Advanced Technology Laboratory, Bothell, Washington, USA) in four standard views. Images were digitised by an integrated online system (Kodak) to produce loops of a single cardiac cycle in each view. Two experienced observers scored systolic wall thickening according to the American Society of Echocardiography's 16 segment left ventricular model. Differences of opinion were resolved by consensus. Systolic wall thickening in

Abbreviations: $\mathrm{AMI}$, acute myocardial infarction; $\mathrm{Cl}$, confidence interval; DSE, dobutamine stress echocardiography; EDIC, echo dobutamine international cooperative; HR, hazard ratio; LVEF, left ventricular ejection fraction; SWTI, systolic wall thickening index 
individual segments was scored as 1 (normal), 2 (reduced), 3 (absent), or 4 (paradoxical). Systolic wall thickening index (SWTI) was calculated by adding up the individual scores in each of 16 segments and divided by the total number of segments (that is, 16).

\section{Dobutamine echocardiography}

After resting images had been acquired, dobutamine infusion was started at $5 \mu \mathrm{g} / \mathrm{kg} / \mathrm{min}$ for five minutes and then increased to 10 and then $15 \mu \mathrm{g} / \mathrm{kg} / \mathrm{min}$ each for five minutes. Low dose images were acquired during this phase before heart rate significantly increased. The dobutamine infusion was then increased to $40 \mu \mathrm{g} / \mathrm{kg} / \mathrm{min}$ in $5 \mu \mathrm{g} / \mathrm{kg} / \mathrm{min}$ increments every three minutes until $75 \%$ of the age predicted target heart rate was reached. If the target heart rate was not achieved atropine was given in $200 \mu \mathrm{g}$ boluses up to a maximum of $1.2 \mathrm{mg}$. High dose images were acquired before the dobutamine infusion was discontinued. The test was terminated early if there was chest pain, ST segment deviation $\geqslant 2 \mathrm{~mm}$ from baseline, hypotension $(<90 \mathrm{~mm} \mathrm{Hg}$ or a drop $>40 \mathrm{~mm} \mathrm{Hg}$ ), hypertension (systolic $>200 \mathrm{~mm} \mathrm{Hg}$ or diastolic $>110 \mathrm{~mm} \mathrm{Hg}$ ), or intolerable symptoms. Images were displayed side by side for wall thickening analysis. Two experienced observers analysed wall thickening from the same 16 segment model.

\section{Follow up}

Study patients were followed up in a dedicated clinic for at least six months. Subsequent follow up was by letter and telephone. Details of clinical events were obtained from the patient or relatives, from the general practitioner, or by review of the clinical notes. The vital status of all screened patients was determined from the hospital patient information system at the termination of the study. Primary study end points were all cause death and non-fatal myocardial infarction, which were assessed for all patients.

\section{Statistical analysis}

Power calculations were based on local outcome data ${ }^{4}$ to achieve significance at the $5 \%$ level with $80 \%$ power over a similar follow up duration. Continuous data are presented as mean (SD) or as median with range if not normally distributed. Differences between means were calculated with an unpaired $t$ test. Differences between proportions were calculated by a one way analysis of variance. Cox univariate logistic regression analysis was performed for continuous and categorical variables to predict time dependant study end points. Multiple logistic regression analysis was then performed including all variables with $p<0.05$ by forward elimination. Regression analysis was then repeated with variables forced into the analysis based on the order in which they are acquired in clinical practice. In this way a series of models was generated with $\chi^{2}$ values for each model. The log rank test was used to compare sequential models. A probability value of $\mathrm{p}<0.05$ was considered significant. Data were analysed with SPSS 11.0 (SPSS Inc, Chicago, Illinois, USA).

\section{RESULTS}

A total of 620 patients were screened for entry into the study. Of these, 501 had confirmed AMI and $212(42 \%)$ of them were recruited. Of those not included in the study, 47 (9\%) died early after AMI and 84 (17\%) were excluded for ongoing clinical instability. A further 95 patients were excluded because of consent refusal (45), inability to undergo DSE in a timely fashion (41), or inability to attend follow up (9).

Table 1 lists the demographic characteristics of the study cohort. Compared with the excluded group, there was no difference in proportion of male patients or of those receiving thrombolysis, or in mean peak creatine kinase or creatine kinase MB fraction, although excluded patients were significantly older $(\mathrm{p}=0.01)$ and less likely to have diabetes $(\mathrm{p}=0.03)$. Comparison between the study cohort and the logistic/refusal group showed a significant differences in

Table 2 Reason for termination of dobutamine stress test

\begin{tabular}{ll}
\hline Achieved target heart rate & $149(70 \%)$ \\
Chest pain & $25(12 \%)$ \\
Ventricular arrhythmia (including multiple ventricular & $11(5 \%)$ \\
extrasystoles and salvos) & $7(3 \%)$ \\
Hypotension (<90 mm Hg or drop $>40 \mathrm{~mm} \mathrm{Hg})$ & $6(3 \%)$ \\
Achieved maximum dose & $6(3 \%)$ \\
Extensive wall motion abnormality & $2(1 \%)$ \\
ST depression $>2 \mathrm{~mm}$ & $1(0.5 \%)$ \\
Hypertension (systolic $>220 \mathrm{~mm} \mathrm{Hg})$ & $5(2 \%)$ \\
Other & \\
\hline
\end{tabular}

Table 1 Demographic characteristics of 495 patients with confirmed myocardial infarction available for follow up

\begin{tabular}{|c|c|c|c|c|c|}
\hline & $\begin{array}{l}\text { Study } \\
\text { population } \\
(\mathrm{n}=212)\end{array}$ & $\begin{array}{l}\text { Excluded } \\
\text { clinically } \\
(n=197)\end{array}$ & p Value* & $\begin{array}{l}\text { Refused/logistic } \\
\text { reasons }(n=86)\end{array}$ & p Value* \\
\hline \multicolumn{6}{|l|}{ Risk factor } \\
\hline Age (years) & $61(12)$ & $66(14)$ & 0.01 & 71 (12) & $<0.001$ \\
\hline Men & $153(72 \%)$ & $130(66 \%)$ & NS & $55(64 \%)$ & NS \\
\hline DM & $42(20 \%)$ & $18(9 \%)$ & 0.03 & $18(21 \%)$ & NS \\
\hline Hypertension & 82 (39\%) & NA & & NA & \\
\hline Prior AMI & $30(14 \%)$ & NA & & NA & \\
\hline CABG & $2(1 \%)$ & NA & & NA & \\
\hline \multicolumn{6}{|l|}{ Current admission } \\
\hline Anterior MI & $95(45 \%)$ & NA & & NA & \\
\hline$Q$ wave $M I$ & $119(70 \%)$ & NA & & NA & \\
\hline Thrombolysis & $155(73 \%)$ & $154(78 \%)$ & NS & $66 \%$ & NS \\
\hline Peak CK (IU) & 1977 (1796) & $1497(1124)$ & NS & 1741 (2019) & NS \\
\hline Peak CK-MB (IU) & $175(148)$ & 143 (133) & NS & $166(173)$ & NS \\
\hline \multicolumn{6}{|l|}{ Outcome } \\
\hline Mortality & $27(13 \%)$ & 87 (44\%) & $<0.001$ & $8(9 \%)$ & NS \\
\hline $\begin{array}{l}\text { Data are mean }(S D) \\
\text { *Difference from stu } \\
\text { AMI, acute myocaro } \\
\text { mellitus; MI, myocar }\end{array}$ & $\begin{array}{l}\%) . \\
\text {; CABG, coro }\end{array}$ & ry artery bypa & surgery; & , creatine kinase; & 1, diabetes \\
\hline
\end{tabular}


Table 3 Cox regression analysis for the prediction of both study end points

\begin{tabular}{|c|c|c|c|c|}
\hline \multirow[b]{2}{*}{ Predictor } & \multicolumn{2}{|l|}{ Death } & \multicolumn{2}{|c|}{ Death or MI } \\
\hline & $\chi^{2}$ & p Value & $\chi^{2}$ & p Value \\
\hline \multicolumn{5}{|l|}{ Clinical } \\
\hline Age & 8.5 & 0.004 & 6.0 & 0.01 \\
\hline Sex (male) & 0.8 & NS & 0.3 & NS \\
\hline DM & 0.6 & NS & 0.2 & NS \\
\hline Previous AMI & 3.0 & NS & 2.4 & NS \\
\hline Anterior AMI & 0.1 & NS & 0.6 & NS \\
\hline$Q$ wave infarction & 0.9 & NS & 1.5 & NS \\
\hline Thrombolysis & 0.9 & NS & 1.0 & NS \\
\hline Peak CK & 0.9 & NS & 0.0 & NS \\
\hline \multicolumn{5}{|l|}{ Echocardiography } \\
\hline SWTI - rest & 6.4 & 0.01 & 3.2 & 0.08 \\
\hline SWTI - low dose & 10.2 & 0.001 & 7.3 & 0.008 \\
\hline SWTI - peak dose & 6.3 & 0.01 & 4.0 & $<0.05$ \\
\hline MVD (echocardiographic) & 5.5 & 0.02 & 1.3 & NS \\
\hline Infarct size* & 8.1 & 0.004 & 5.5 & 0.02 \\
\hline Extent of ischaemiat & 0.2 & NS & 0.4 & NS \\
\hline
\end{tabular}

*Number of non-viable segments; tnumber of ischaemic segments. MVD, multivessel disease; SWTI, systolic wall thickening index.

mean age $(\mathrm{p}<0.001)$ only. At discharge $66 \%$ were taking $\beta$ blockers, 56\% were taking angiotensin converting enzyme inhibitors, $74 \%$ were taking statins, and $91 \%$ were taking aspirin.

\section{Follow up}

Follow up data were available for all 212 included patients. The mean (SD) duration of follow up for surviving patients was 803 (297) days. An adverse outcome occurred in 39 patients $(18 \%)$, of whom 27 died and 16 had a non-fatal myocardial infarction. Ninety eight patients (46\%) underwent a revascularisation procedure during the course of the study. The mean (SD) delay from presentation to revascularisation was 157 (183) days.

Vital status follow up was available for all but six (99\%) of the entire screened population with confirmed myocardial infarction. Included patients had a significantly lower mortality (13\%) than the excluded population (44\%) $(p<0.001)$. The mortality of patients who refused consent or who were excluded on logistic grounds was not significantly lower $(9 \%)$ than that of the study population.

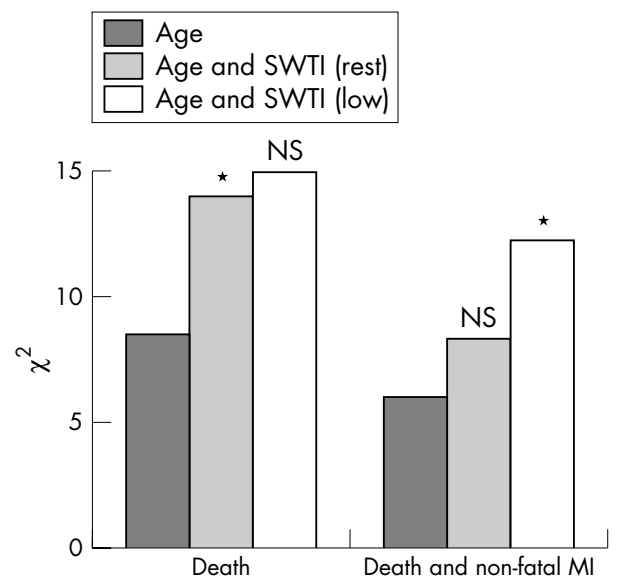

Figure 1 Histogram showing the incremental information provided by systolic wall thickening index (SWTI) during low dose dobutamine echocardiography in addition to resting echocardiography and age for prediction of death and of death or non-fatal myocardial infarction (MI) in the entire study cohort. NS, not significant. ${ }^{*} \mathrm{p}<0.05$.

\section{DSE safety and haemodynamic data}

DSE was performed 4.8 (1.5) days after myocardial infarction. All but seven patients were studied after adequate cessation of $\beta$ blocker. The mean maximum heart rate was 129 (16) beats/min. The target heart rate was achieved by 149 patients $(70 \%)$ (table 2$)$. One patient experienced an episode of self terminating ventricular tachycardia during the dobutamine infusion and 53 experienced chest pain, of whom two developed ST segment elevation.

\section{Echocardiographic data}

All but three $(99 \%)$ patients had evidence of systolic wall thickening abnormalities at rest. The mean SWTI at rest was 1.6 (0.4). However, 94 (44\%) had evidence of contractile reserve and the mean SWTI fell to 1.5 (0.4) when dobutamine was infused at low dose. Eighty (38\%) patients had ischaemia and 47 (22\%) had echocardiographic evidence of multivessel disease.

\section{Prediction of death}

The univariate predictors of death were age $\left(\chi^{2}=8.5\right)$, infarct size $\left(\chi^{2}=8.1\right)$, echocardiographic multivessel disease $\left(\chi^{2}=5.5\right)$, SWTI at rest $\left(\chi^{2}=6.4\right)$, SWTI after low dose dobutamine $\left(\chi^{2}=10.2\right)$, and SWTI after peak dose dobutamine $\left(\chi^{2}=6.3\right)$ (table 3$)$. The only multivariate predictors of death were age (hazard ratio (HR) 1.04/year, $95 \%$ confidence interval $(\mathrm{CI}) 1.01$ to $1.08, \mathrm{p}=0.01)$ and SWTI after low dose dobutamine (HR 3.6, 95\% CI 1.4 to 9.3 , $\mathrm{p}=0.007)$.

In the incremental analysis resting function provided incremental information in addition to age $(p=0.03)$, but low dose wall thickening did not provide any significant incremental benefit $(p=0.1)$ (fig 1). Figure 2 depicts a Kaplan-Meier survival curve showing the impact of wall motion score index at low dose dobutamine on mortality.

\section{Prediction of death or non-fatal MI}

The univariate predictors of death or non-fatal AMI were age $\left(\chi^{2}=6.0\right)$, infarct size $\left(\chi^{2}=5.5\right)$, SWTI after low dose dobutamine $\left(\chi^{2}=7.3\right)$, and SWTI at peak dose dobutamine $\left(\chi^{2}=4.0\right)$ (table 3$)$. The multivariate predictors of this end point were age (HR 1.03/year, 95\% CI 1.00 to 1.06 ; p = 0.04) and SWTI after low dose dobutamine (HR 2.5, 95\% CI 1.2 to 5.5; $\mathrm{p}=0.02$ ). For this end point resting echocardiographic function did not provide an incremental benefit over age, but echocardiographic analysis at low dose dobutamine did provide significant additional information $(p=0.02)$ (fig 1$)$.

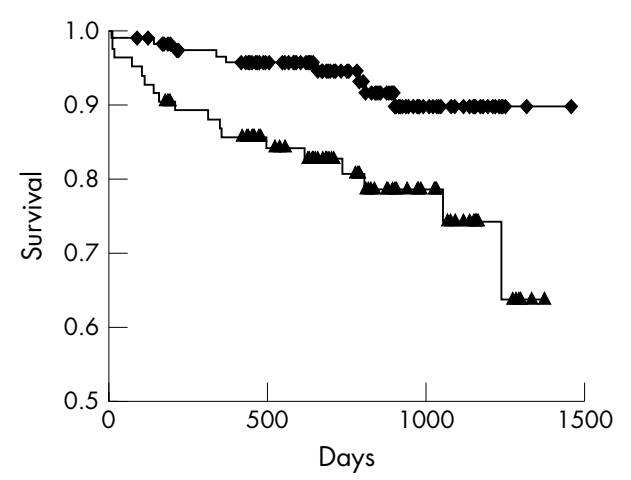

Figure 2 Kaplan-Meier curve showing the impact on mortality of a wall motion score index at low dose dobutamine of $\leqslant 1.6$ (diamonds) compared with a score of $>1.6$ (triangles); $n=212$, log rank test $\mathrm{p}=0.005$. 
Table 4 Cox regression analysis for study end points in medically treated patients

\begin{tabular}{|c|c|c|c|c|}
\hline \multirow[b]{2}{*}{ Predictor } & \multicolumn{2}{|c|}{ Death } & \multicolumn{2}{|c|}{ Death or MI } \\
\hline & $\bar{\chi}^{2}$ & p Value & $\bar{\chi}^{2}$ & p Value \\
\hline \multicolumn{5}{|l|}{ Clinical } \\
\hline Age & 5.9 & 0.02 & 6.1 & 0.01 \\
\hline \multicolumn{5}{|l|}{ Echocardiography } \\
\hline SWTI - rest & 4.4 & 0.04 & 5.6 & 0.02 \\
\hline SWTI - low dose & 6.1 & 0.01 & 7.9 & 0.005 \\
\hline SWTI - peak dose & 7.1 & 0.008 & 9.1 & 0.003 \\
\hline MVD & 5.9 & 0.02 & 7.2 & 0.007 \\
\hline Infarct size ${ }^{*}$ & 4.8 & 0.03 & 6.2 & 0.01 \\
\hline
\end{tabular}

\section{Medically treated patients}

SWTI at peak dose dobutamine was the only multivariate predictor of death (HR 3.5, 95\% CI 1.4 to 9.1; $p=0.009$ ) and the combined end point of death or non-fatal AMI (HR 3.9, 95\% CI 1.6 to $9.6 ; p=0.003)$ in patients who were not revascularised (table 4 ).

\section{DISCUSSION}

It has long been known that LVEF is a key determinant of outcome after AMI. ${ }^{10}$ However, LVEF six months after myocardial infarction is a better predictor of mortality than ejection fraction measured acutely. ${ }^{11}$ It has been shown that low dose DSE evidence of myocardial viability after AMI was the best predictor of subsequent improvement in LVEF. ${ }^{12}$ This study combines these findings and shows that low dose DSE evidence of myocardial viability is the strongest univariate predictor of both death and death or myocardial infarction and the best independent predictor of long term survival of stable patients early after AMI. Information from DSE furthermore is incremental over the resting left ventricular function. However, in the group of patients who did not undergo revascularisation, evidence of ischaemia by high dose DSE predicted mortality.

\section{Comparison with other studies: impact of viability}

Carlos $e t$ al $^{5}$ studied 214 patients who were followed up for at least 500 days after AMI and reported that lack of myocardial viability of the infarct zone was highly predictive of an adverse outcome (combined hard and soft events but not death). In particular, they found that patients with large but viable infarcts had a similar prognosis to those with small infarcts. Previtali et $a l^{6}$ showed that patients with viability and no ischaemia have an excellent prognosis but found no independent prognostic role for myocardial viability.
However, in the EDIC (echo dobutamine international cooperative) study ${ }^{7}$ consisting of 778 patients and in a study by Nijland $e t$ al $^{8}$ the presence of viability was associated with an excess of episodes of unstable angina but had no impact on the prediction of hard events (death or non-fatal AMI). The EDIC authors hypothesised that the benefits of viability were only modest in patients with reasonably preserved ventricular function (mean resting SWTI 1.5) and were outweighed by the "unstable substrate" for further events. This is supported by data published by Anselmi et al, "who found more non-fatal cardiac events in medically treated patients with viability than without viability and by a reanalysis of the EDIC patients with SWTI $>1.6$ and who were treated medically. However, in this group with severe left ventricular dysfunction the presence of viability did exert a protective effect on survival. ${ }^{13}$

The present study, however, is the first to show that the presence of myocardial viability is an independent predictor of survival. Table 5 summarises the differences between the present and aforementioned studies. The resting left ventricular function in our study was similar to that in the original EDIC study, so the difference in results cannot be explained on the basis of left ventricular dysfunction. Variation in rates of revascularisation is another possible explanation for the differences, since revascularised viable tissue would be expected to recover and contribute to resting function with resultant mortality benefits and the potential detrimental effect of further ischaemia would have been removed. However, we believe that the most likely explanation for the difference between our results and the results of all previous studies is the increased number of hard events, which is related in part to the patient population and almost certainly to the length of follow up, which is the longest of such patients reported to date.

\section{Comparison with other studies: impact of ischaemia}

In several studies DSE evidence of the presence and extent of myocardial ischaemia was an independent predictor of outcome after AMI. ${ }^{5-7} 1415$ Furthermore, patients with preserved left ventricular function $(\geqslant 40 \%)$ who have no evidence of ischaemia have an excellent long term outcome. ${ }^{15}$ In our study, however, ischaemia was a predictor of outcome only of patients who were not revascularised, probably because the relatively high rate of revascularisation had the effect of diminishing the significance of this variable for analysis of the whole cohort.

\section{Limitations}

Whether to perform a coronary revascularisation procedure was decided on anatomical grounds by physicians who were

Table 5 Differences between studies reporting the impact of myocardial viability assessed by low dose dobutamine stress echocardiography on outcome

\begin{tabular}{|c|c|c|c|c|c|}
\hline & \multicolumn{5}{|l|}{ Study } \\
\hline & Present & Carlos $^{5}$ & Sicari $^{7}$ & Previtali $^{6}$ & Nijland $^{8}$ \\
\hline Patients & All stable & All stable & $\begin{array}{l}1 \text { st } \mathrm{AMl},<76 \\
\text { years, stable }\end{array}$ & 1st AMI, stable & $\begin{array}{l}\text { Stable, }<76 \\
\text { years }\end{array}$ \\
\hline Consecutive recruitment & Yes & Yes & Yes & Yes & Yes \\
\hline Number & 212 & 214 & 778 & 152 & 138 \\
\hline Follow up (months) & $26(10)$ & $16(6)$ & $9(7)$ & $15(19)$ & $19(7)$ \\
\hline SWTI & 1.6 & 1.9 & 1.5 & NA & 1.6 \\
\hline Death & $13 \%$ & NA & NA & $3 \%$ & $4 \%$ \\
\hline Cardiac death & NA & $7 \%$ & $2 \%$ & NA & NA \\
\hline $\mathrm{AMI}$ & $8 \%$ & $7 \%$ & $3 \%$ & $4 \%$ & $1 \%$ \\
\hline Hard events & $18 \%$ & $14 \%$ & $5 \%$ & $7 \%$ & $6 \%$ \\
\hline Revascularisation & $46 \%$ & $39 \%$ & $22 \%$ & $44 \%$ & $28 \%$ \\
\hline
\end{tabular}


responsible for patient management. However, these physicians were blinded to the stress echocardiogram results. Also, coronary angiography was not a study requirement, so the relative prognostic impact of angiography and the impact of infarct related arterial patency could not be compared with stress echocardiography. We studied consecutive, consenting, stable patients admitted to our institution and did not exclude patients with previous myocardial infarction. In some instances this made determination of the infarct territory difficult; however, it makes our results more applicable to the caseload of a typical district general hospital.

Because of ethical concerns about the possible adverse impact of stressing patients so early after AMI our target peak heart rate was only $75 \%$ of the age predicted maximum, compared with a target of $85 \%$ for patients with stable coronary disease. This may have resulted in a reduced sensitivity for detection of ischaemia and consequently for predicting outcome in the entire study cohort. However, despite this, in the subgroup of patients who were not revascularised, inducible ischaemia still predicted outcome.

\section{Conclusion}

This study adds to the available data showing that DSE is a powerful predictor of outcome of stable survivors of AMI and provides evidence that the presence of myocardial viability detected by DSE has a positive impact on survival.

\section{Authors' affiliations}

J M A Swinburn, R Senior, Department of Cardiovascular Medicine, Northwick Park Hospital, Harrow, Middlesex, UK

This study is funded by the Cardiac Research Fund.

\section{REFERENCES}

1 Braunwald E, Kloner RA. The stunned myocardium: prolonged, postischemic ventricular dysfunction. Circulation 1982;66:1146-9.

2 Afridi I, Grayburn PA, Panza JA, et al. Myocardial viability during

dobutamine echocardiography predicts survival in patients with coronary artery disease and severe left ventricular systolic dysfunction. J Am Coll Cardiol 1998;32:921-6.

3 Senior R, Kaul S, Lahiri A. Myocardial viability on echocardiography predicts long-term survival after revascularisation in patients with ischaemic congestive heart failure. J Am Coll Cardiol 1999;33:1848-54

4 Basu S, Senior R, Dore C, et al. Value of thallium-201 imaging in detecting adverse cardiac events after myocardial infarction and thrombolysis: a follow up of 100 consecutive patients. BMJ 1996:313:844-8.

5 Carlos ME, Smart SC, Wynsen JC, et al. Dobutamine stress echocardiography for risk stratification after myocardial infarction. Circulation 1997; 95: 1402-10.

6 Previtali M, Fetiveau R, Lanzarini L, et al. Prognostic value of myocardial viability and ischaemia detected by dobutamine stress echocardiography early after acute myocardial infarction treated with thrombolysis. J Am Coll Cardiol 1998;32:380-6.

7 Sicari R, Picano E, Landi $P$, et al. Prognostic value of dobutamine-atropine stress echocardiography early after acute myocardial infarction. Echo dobutamine international cooperative (EDIC) study. J Am Coll Cardiol 1997;29:254-60.

8 Niiland FM, Kamp O, Verhorst PM. In-hospital and long-term prognostic value of viable myocardium detected by dobutamine echocardiography early after acute myocardial infarction and its relation to indicators of left ventricular systolic dysfunction. Am J Cardiol 2001;88:949-55.

9 Anselmi M, Golia G, Cicoira M, et al. Prognostic value of detection of myocardial viability using low-dose dobutamine echocardiography in infarcted patients. Am J Cardiol 1998;81:21G-8G.

10 Volpi A, De Vita C, Franzosi MG, et al. Determinants of 6-month mortality in survivors of myocardial infarction after thrombolysis: results of the GISSI-2 data base. The Ad hoc Working Group of the Gruppo Italiano per lo Studio della Sopravvivenza nell'Infarto Miocardico (GISSI)-2 Data Base. Circulation 1993;88:416-29.

11 Brodie BR, Stuckey TD, Kissling G, et al. Importance of infarct-related artery patency for recovery of left ventricular function and late survival after primary angioplasty for acute myocardial infarction. J Am Coll Cardiol 1996;28:319-25.

12 Nijland F, Kamp O, Verhorst PM, et al. Early prediction of improvement in ejection fraction after acute myocardial infarction using low dose dobutamine echocardiography. Heart 2002;88:592-6.

13 Picano E, Sicari R, Landi P, et al. Prognostic value of myocardial viability in medically treated patients with global left ventricular dysfunction early after an acute uncomplicated myocardial infarction: a dobutamine stress echocardiographic study. Circulation 1998;98:1078-84.

14 Bigi R, Desideri A, Galati A, et al. Incremental prognostic value of stress echocardiography as an adjunct to exercise electrocardiography after uncomplicated myocardial infarction. Heart 2001;85:417-23.

15 Bigi R, Cortigiani L, Mariani PR, et al. Sustained favorable long-term prognosis of negative stress echocardiography following uncomplicated myocardial infarction. Am J Cardiol 2002;90:149-52.

\section{IMAGES IN CARDIOLOGY}

\section{Angiographic appearance of "tumour blush" produced by a large right atrial myxoma}

A

76 year old woman presented to our institution with shortness of breath. The initial evaluation included a computed tomographic (CT) scan to exclude pulmonary embolism. However, the CT scan demonstrated a large right atrial mass which was confirmed by echocardiography. The patient was referred for coronary angiography before resection of this mass. A right atrial angiogram showed a large mobile filling defect measuring $6 \mathrm{~cm}$ in diameter in the right atrium prolapsing into the right ventricle in diastole. Coronary angiography showed no significant coronary artery disease. The right coronary artery injection showed an atrial branch of the right coronary artery supplying this tumour producing a "tumour blush" (panel). The patient underwent surgical excision of the mass with patch reconstruction of the atrial septum. The final pathological diagnosis was atrial myxoma.

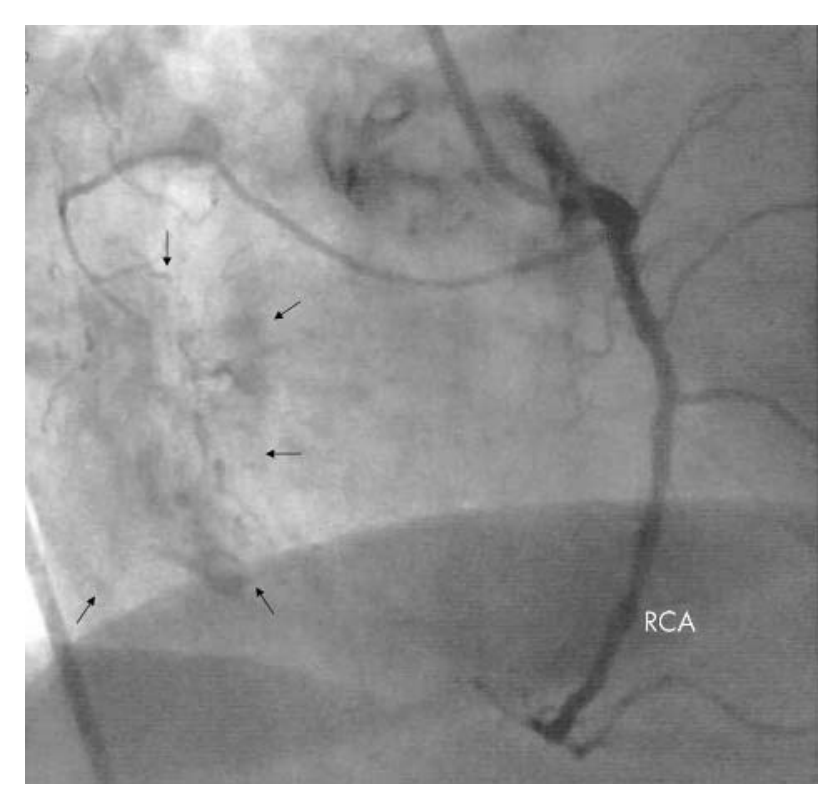

